it has alone the theoretical advantage of in- leukaemia-a very rare coincidence. Blood ducing immune tolerance, ${ }^{1}$ has a suppressive was taken from the patient a day after effect on experimental autoimmune disease, ${ }^{2}$ leukaemia was diagnosed. Lymphocytes were and is more effective than other alkylating separated as described by Hughes and agents in suppressing antibody production. ${ }^{3}$ Caspary, ${ }^{1}$ the procedure taking about $2 \frac{1}{2}$

Accepting the fact that patients may be hours. The patient was admitted again for too few for a controlled trial, I feel that obstetric reasons at 38 weeks and the baby patients given treatment of this type should was born four days later. Blood was taken have frequent scientific assessment of the immediately from the umbilical cord and an activity of their disease. In the case of S.L.E. hour later from the mother. A third specimen one might expect a record of frequent of blood was taken from the mother three estimations of $\alpha_{2}$-globulins, complement weeks later. From all samples of blood components, cryoglobulins, serum DNA, and lymphocytes were separated and embedded RNA antibodies, as well as L.E. cells and with the same procedure as described in antinuclear factor.-I am, etc.,

E. N. WARDLE

Wellcome Research Laboratories,

Royal Victoria Infirmary,

1 Dukor, P., and Dietrich, F. M., International Archives of Allergy, 1968, 34, 32 .

Gerebtzoff, A., Lambert, P. H., and Miescher, P. A Annual Review of Pharmacology, 1972, $12,287$.

emmell, E., Hurd, E. R., and Ziff, M., Clinical and Experimental Immunology, 1971, 8, 355.

\section{Treatment of Systemic Lupus} Erythematosus

SIR,-With reference to the report by Dr. M. L. Snaith and his colleagues (28 April, p. 197) concerning the choice of immunosuppressive drugs in systemic lupus erythematosus, our experience has been that the marrow-depressant effect of azathioprine when used in the treatment of rheumatoid arthritis in a dose of $2.5 \mathrm{mg} / \mathrm{kg} / \mathrm{day}$ or cyclophosphamide in a dose of $1.5 \mathrm{mg} / \mathrm{kg} /$ day has been relatively easily controlled with adequate monitoring of the blood, including platelet counts.

An important difference, however, has been the effect of cyclophosphamide on fertility in the male. We found that six male patients on azathioprine had entirely normal sperm counts. In contrast, of six males on cyclophosphamide, five were found to be azoospermic and one had a count of only 5 million $/ \mathrm{ml}$. If chlorambucil produced amenorrhoea in four of six patients in Dr. Snaith's series, it seems likely that its effect on fertility is similar to that of cyclophosphamide.

We would suggest, therefore, that there are strong grounds for first considering azathioprine when an immunosuppressive agent is indicated in young patients with connective tissue disorders.-We are, etc.

Michael Mason A. M. BROWNJOHN JACQUELINE HARRIS JOHN WOODLAND

The London Hospital

London E.1

\section{Surface Particles on Leukaemic Lymphocytes}

SIR,-In a previous letter (20 January, p. 172) I reported the presence of surface particles on leukaemic lymphocytes from five cases of chronic lymphatic leukaemia and one of acute leukaemia.

After this report had been published a patient aged 41 who was 26 weeks pregnant was diagnesed as having chronic lymphatic detail elsewhere. ${ }^{2}$

Membrane blebs on the surface of the lymphocytes were a striking feature of the first sample of maternal blood (fig. 1).

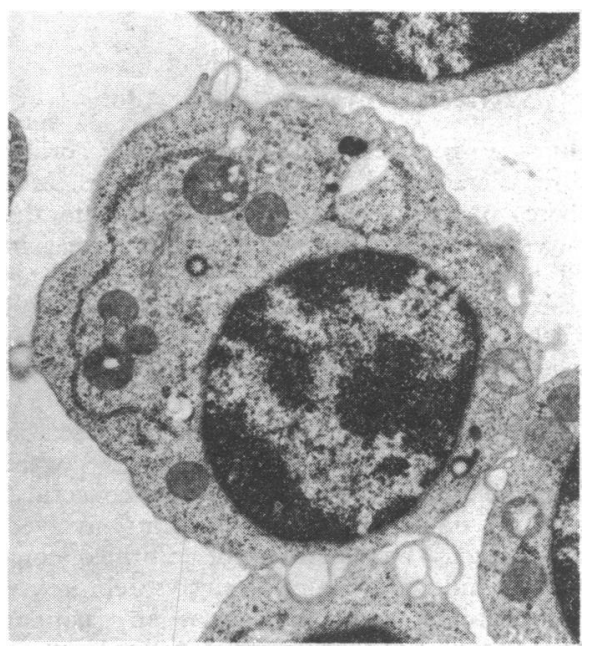

Though these blebs were present on the surface of lymphocytes in the second and third samples they did not appear to be as common as in the first. Most of the lymphocytes from the second sample contained granular dense structures similar to those of polymorphs. In all three samples from the mother, besides the blebs, particles were seen budding from the surface of the lymphocytes and a few were free, as described in my previous letter (figs. 1 and 2).

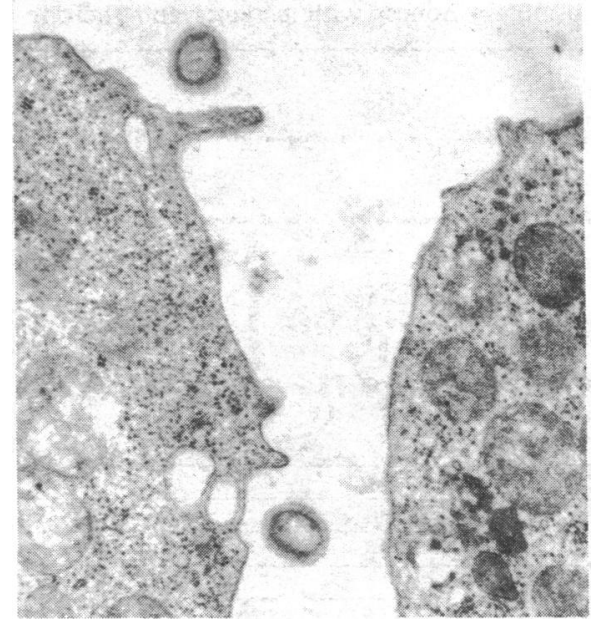

Lymphocytes from the umbilical cord blood appeared quite normal, though they showed pseudopodia; they did not have blebs or particles similar to those in the lymphocytes of the mother (fig. 3).

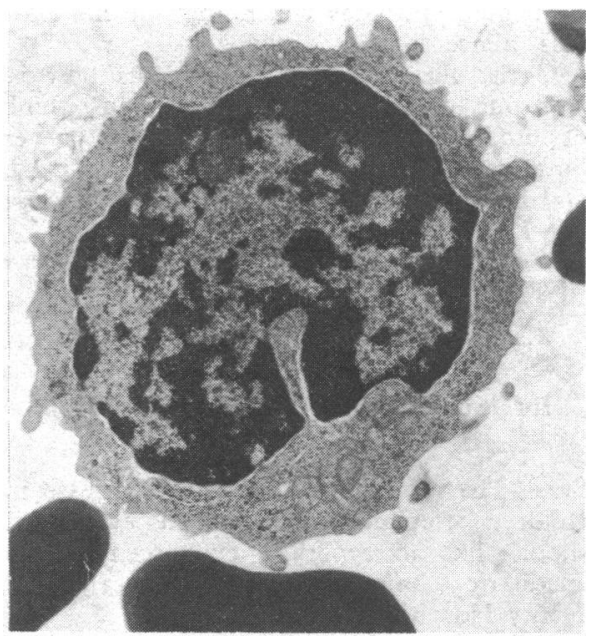

It has been thought that surface blebs might be artefacts due to the fixation and embedding technique, but the present study clearly indicates the presence of surface blebs and particles in the lymphocytes of the mother with chronic lymphatic leukaemia, as in the other six leukaemic patients studied, while their absence from the lymphocytes from the cord blood and from those of normal subjects does indicate their relationship to the disease. It must be borne in mind that the random sampling variations in the electron microscope may easily give a misleading assessment of the frequency with which a particular structure is encountered, and that this difficulty is increased by the possibility of artefacts even in seemingly "well fixed" material. Although 10 times more lymphocyte blocks were cut from the cord blood sample than from the samples from the mother, there was no evidence that maternal lymphocytes are to be found in the blood of the child.

I would like to thank Dr. F. Clark for his courtesy in allowing access to his patients. -I am, etc.

Demyelinating Diseases Unit,

H. K. NARANG Medical Research Council,

Newcastle General Hospita

1 Hughes, D., and Caspary, E. A., International Archives of Allergy, 1970 , 37, 506.
2 Narang, H. K. Fournal of Hygiene, 1973. In press.

FIG. 1-Lymphocytes from 41-year-old leukaemic patient 26 weeks pregnant. Note the surface blebs and particles. $x 11,240$

FIG. 2-Lymphocytes from the same patient showing two free virus-like particles. $x$ 19,35s.

(w). blood of $x 8,765$

\section{Mute of Malady}

SIR,-With reference to your leading article (31 March, p. 755), elucidation of the underlying cause of mutism may be helped by demonstration of thought content. This may confirm a diagnosis of schizophrenic or depressive stupor and can be helpful in the management of elective mutism and some conversion symptoms.

A time-honoured method of achieving this in adults is by amylobarbitone sodium abreaction. I Investigators of mute patients, however, are understandably reluctant to administer a powerful central nervous system depressant to patients who may have grave organic brain damage or be suffering from drug effects. Intravenous diazepam has been 
found in practice to be of equal value and also safe in the diagnosis of two small series of mute psychiatric inpatients. ${ }^{2} 3$

"Poor-risk" patients, especially those susceptible to respiratory or cardiovascular de pression, will need extra care, but even then intravenous diazepam and lorazepam have been shown to be less hazardous than intravenous barbiturates. ${ }^{4}$ Care is also necessary with epileptics receiving parenteral barbiturates or paraldehyde, ${ }^{5}$ patients taking Mandrax $^{6}$ and during curarization. ${ }^{7}$ Apnoea with diazepam alone has been reported in an 80-year-old patient. 8 Such risks must be balanced against the importance of diagnosing and treating the underlying cause of the mutism.-I am, etc.,

Airedale General Hospital.

H. G. EGDELI

Keighley, York

1 Sargent, W., and Slater, E., An Introduction to Physical Methods of Treatment in Psychiatry p. 145. London, Churchill Livingstone, Psych lished).

lished).

tion fournal, 1971, 16, 445

Knapp, R. B., and Fierre, L., in Excerpto Medic International Congress Series 1972, No. 261, 89.

5 Bell, D. S., British Medical fournal, 1969, 1, 159. Doughty, A., British Medical fournal, 1970, 2

Cheymol, J., Driessche, J., van den, Allain, P. Réanimation, 1967, 24, 329.

Buskop, J. J., Price, M., and Molnar, I., Ne
England fournal of Medicine, 1967, 277, 316.

\section{Shake Test on Amniotic Fluid and the} Respiratory Distress Syndrome

SIR,-May we comment on the findings of Dr. S. G. Bhagwanani and others (24 March, p. 697)? We can confirm that a negative shake test ${ }^{1}$ on amniotic fluid is of poor predictive value for respiratory distress syndrome (R.D.S.) whereas a positive zon result reflects the absence of risk of R.D.S

From our study of 86 shake tests performed on amniotic fluid obtained by amniocentesis or hindwater amniotomy with in 36 hours of delivery at 34 to 42 weeks' gestation 58 gave positive zone results, 17 gave intermediate zone results, and 11 gave negative zone results. Of the 86 only on neonate (34 weeks' gestation) with a negative shake test and lecithin concentration of $3.88 \mathrm{mg} / 100 \mathrm{ml}$ showed any evidence of R.D.S., but this was attributed to maternal chlormethiazole therapy for severe preeclampsia during labour. On 54 specimens obtained from 50 of the 86 cases lecithin concentrations were estimated by the method of Bhagwanani et al. ${ }^{2}$ The means and ranges for each shake test (see table) are comparable with her data.

Means and Ranges of Amniotic Fluid Lecithin Concentration Re'ated to Shake Test Zone

\begin{tabular}{l|c|c|c}
$\begin{array}{c}\text { Shake Test } \\
\text { Zone }\end{array}$ & $\begin{array}{c}\text { No. } \\
\text { of } \\
\text { Cases }\end{array}$ & $\begin{array}{c}\text { Mean } \\
\text { Lecithin } \\
\text { Concentration } \\
(\mathrm{mg} / 100 \mathrm{ml})\end{array}$ & $\begin{array}{c}\text { Range of } \\
\text { Lecithin } \\
\text { Concentration } \\
(\mathrm{mg} / 100 \mathrm{ml})\end{array}$ \\
\hline Negative & 12 & $4 \cdot 17$ & $3 \cdot 18-7 \cdot 50$ \\
\hline Intermediate & 13 & $8 \cdot 40$ & $4 \cdot 50-17 \cdot 0$ \\
\hline Positive & 29 & $19 \cdot 04$ & $10 \cdot 65-28 \cdot 35$ \\
\hline
\end{tabular}

It is interesting to speculate on the significance of our false negative results. Of the 11 cases with negative zone results (34 to 42 weeks' gestation) there was a measured excess of amniotic fluid at hindwater amniotomy in four cases $(2,300 \mathrm{ml}-3,900 \mathrm{ml})$ and an unmeasured great excess in another. These excessive volumes of amniotic fluid may have influenced the interpretation of these shake test results in the prediction of R.D.S. We attribute this to a dilution effect and suggest that this may be one explanation for false negative tests which are dependent on amniotic fluid phospholipid concentrations, because hydramnios is not always apparent clinically. Dr. Bhagwanani reports two cases of pulmonary hypoplasia with low results. We have also encountered this abnormality associated with a negative shake test in a fresh stillbirth with multiple congenital abnormalities, but there was also a gross excess of amniotic fluid $(4,000 \mathrm{ml})$.

Finally, we would like to comment on the critical lecithin concentration of $3.5 \mathrm{mg} / 100$ ml recommended by Dr. Bhagwanani ${ }^{3}$ in relation to the shake test criteria in the prognosis of R.D.S. Definitive pulmonary function tests ${ }^{4}$ were performed on four of the infants with negative zone tests. All four gave normal values for minute volume, lung compliance and lung volume, but two who had had lecithin concentrations of $5.70 \mathrm{mg} / 100$ $\mathrm{ml}$ and $7.35 \mathrm{mg} / 100 \mathrm{ml}$ respectively showed evidence of pulmonary hypoperfusion. The effective pulmonary blood flow values for these infants were $109 \mathrm{ml} / \mathrm{kg} / \mathrm{min}$ and 111 $\mathrm{ml} / \mathrm{kg} / \mathrm{min}$ (normal, $164 \pm 37 \mathrm{ml} / \mathrm{kg} / \mathrm{min}$ ) Pulmonary hypofusion has been shown by Chu et al., ${ }^{5}$ to be an importan factor in the development of R.D.S. In neither of these two cases described was there an excessive volume of amniotic fluid. We suspect that the critical lecithin level may be too low at $3.5 \mathrm{mg} / 100$ $\mathrm{ml}$ if this degree of functional immaturity is to be avoided, and it is at least possible that the apparent margin of safety provided by the shake test is necessary, but we suspect that the critical level lies between those two standards.-We are, etc.

P. M. FISHER H. W. SUTHERLAND

Department of Obstetrics and Gynaecology, University of Aberdeen

R. DINWIDDIE Department of Child Health

G. RUSSELI University of Aberdeen

Clements, J. A., et al., New England fournal of Medicine, 1972, 286, 1077

D. and Turnbull, $A$.

Fahmy, D. and Turnbull, $A$ Dinwiddie, R, and Russell, G., Biology of the
Neonate, 1972, 21, 83 .

5 Chu et al., Pediatrics, 1967, 40, 709.

\section{Fungal Infections of the Spine}

SIR,-The unnamed pathologists who made the diagnosis of cryptococcosis in the case of spinal disease described by Mr. P. Balasubramanian and Professor J. F. Silva (7 April, p. 27) have the thanks of those who are disturbed by the proportion of cases of fungal infection of the spine that goes unrecognized and therefore inappropriately treated. In 20 years I have seen 24 cases of mycosis with predominantly spinal lesions. Only six were diagnosed early enough for successful treatment (three cases of Blastomyces dermatitidis infection, two of cryptococcosis, and one of coccidioidomycosis). In
18 cases the disease was misdiagnosed until too late to prevent paraplegia, fatal secondary sepsis, or extension of the fungal infection (three cases each of $B$. dermatitidis infection, Histoplasma duboisii infection, and cryptococcosis, two each of candidosis and Nocardia brasiliensis infection, and single cases of sporotrichosis and of infection by Histoplasma capsulatum, Phialophora gougerotii, Torulopsis glabrata, and an unidentified myceliate fungus).

Mr. Balasubramaniam and Professor Silva refer to the differential diagnosis of cryptococcosis, tuberculosis, and sarcoidosis. Clinically, meningitis, Addison's disease, and osteitis due to tuberculosis might be confused with the corresponding manifestations of cryptococcosis. Rarely, tuberculosis and cryptococcosis coexist. Histologically, cryptococcosis should not be mistaken for tuberculosis; while every variation of the tissue reaction of tuberculosis is duplicated in cryptococcosis, the fungi are there to be seen, usually without difficulty.

The distinction between cryptococcosis and sarcoidosis should not be a problem. The cryptococcus is exceptionally rarely the cause of a sarcoid reaction. If sarcoid lesions in a proved case of cryptococcosis cannot be shown to contain cryptococci, the explanation is usually that they are in fact lesions of sarcoidosis and not a manifestation of the infection; sarcoidosis is second only to classic Hodgkin's disease in predisposing to cryptococcosis. ${ }^{1}$ Of 188 cases of cryptococcosis that I have seen, $43(23 \%)$ were associated with Hodgkin's disease and $22(12 \%)$ with sarcoidosis. To argue that in these cases there is in reality no sarcoidosis but a peculiar reaction to the fungus that exactly simulates sarcoidosis is merely to parallel the discredited view that because cryptococcosis may be associated with Hodgkin's disease the latter is in those cases not Hodgkin's disease but a peculiar reaction to the fungus that exactly simulates Hodgkin's disease. The important fact is that certain chronic diseases of the lymphoreticular system specifically lower resistance to cryptococcosis (as they do to dormant histoplasmosis, coccidioidomycosis, blastomycoses and-let us not forget it-tuberculosis).

One diagnostic point noted by $\mathrm{Mr}$. Balasubramaniam and Professor Silva needs amplification. As with comparable tuberculous lesions, open operation on fungal lesions of bone carries a substantial risk of secondary bacterial infection, even today. Accurate diagnosis being essential, diagnostic procedures that introduce a hazard must be undertaken with deliberation.-I am, etc.

W. ST. C. SYMMERS

Northwood, Middlesex

1 Symmers, W. St. C., Lancet, 1967, 1, 159.

\section{Bacterial Resistance in the Community}

SIR,-We wish to comment on Dr. J. E. M Whitehead's article (28 A.pril, p. 224) which raises the question of bacterial resistance to commonly used antibiotics as seen in general practice.

Dr. Whitehead implies that penicillinsensitive strains of Staphylococcus aureus are predominant outside hospital. In a recent 15-month study of pathogens causing skin and soft-tissue infections in a general prac- 